\title{
Correction to: Appraisal of chromium in chicken reared on maize irrigated with sewage water
}

\author{
Zill-e-Huma ${ }^{1} \cdot$ Zafar Iqbal Khan ${ }^{1} \cdot$ Ijaz Rasool Noorka $^{2} \cdot$ Kafeel Ahmad $^{1} \cdot$ Kinza Wajid $^{1} \cdot$ Muhammad Nadeem $^{3}$. \\ Mudasra Munir ${ }^{1}$. Ifra Saleem Malik ${ }^{1} \cdot$ Madiha Kiran $^{4} \cdot$ Tahir Hussain $^{4} \cdot$ Muhammad F. Qamar $^{4} \cdot$ Tasneem Ahmad $^{5}$. \\ Saif Ur Rehman ${ }^{6} \cdot$ Muhammad Fahad Ullah $^{7}$
}

Published online: 7 December 2020

(C) Springer-Verlag GmbH Germany, part of Springer Nature 2020

\section{Correction to: Environmental Science and Pollution Research https://doi.org/10.1007/s11356-020-11393-9}

The correct affiliation of Tahir Hussain and Saif Ur Rehman is presented in this paper.

Publisher's note Springer Nature remains neutral with regard to jurisdictional claims in published maps and institutional affiliations.

The online version of the original article can be found at https://doi.org/ $10.1007 / \mathrm{s} 11356-020-11393-9$

Zafar Iqbal Khan

zafar.khan@uos.edu.pk

1 Department of Botany, University of Sargodha, Sargodha, Pakistan

2 Department of Plant Breeding and Genetics, University College of Agriculture, University of Sargodha, Sargodha, Pakistan

3 Institute of Food Science and Nutrition, University of Sargodha, Sargodha, Pakistan

4 Department of Pathobiology, University of Veterinary and Animal Sciences, sub-campus Jhang, Lahore, Pakistan

5 Pakki Thatti R \& D Farm, Toba Tek Singh, Pakistan

6 Institute of Geology, University of the Punjab, Quaid-i-Azam Campus, Lahore, Pakistan

7 Department of Earth Sciences, University of the Punjab, Lahore, Pakistan 